Supplement of Ocean Sci., 13, 521-530, 2017

https://doi.org/10.5194/os-13-521-2017-supplement

(C) Author(s) 2017. This work is distributed under

the Creative Commons Attribution 3.0 License.

(c) (1)

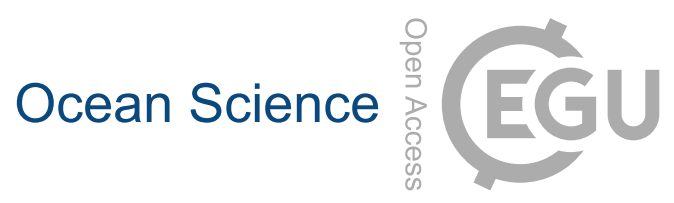

Supplement of

\title{
Freshening of Antarctic Intermediate Water in the South Atlantic Ocean in 2005-2014
}

Wenjun Yao et al.

Correspondence to: Wenjun Yao (wjimyao@gmail.com)

The copyright of individual parts of the supplement might differ from the CC BY 3.0 License. 

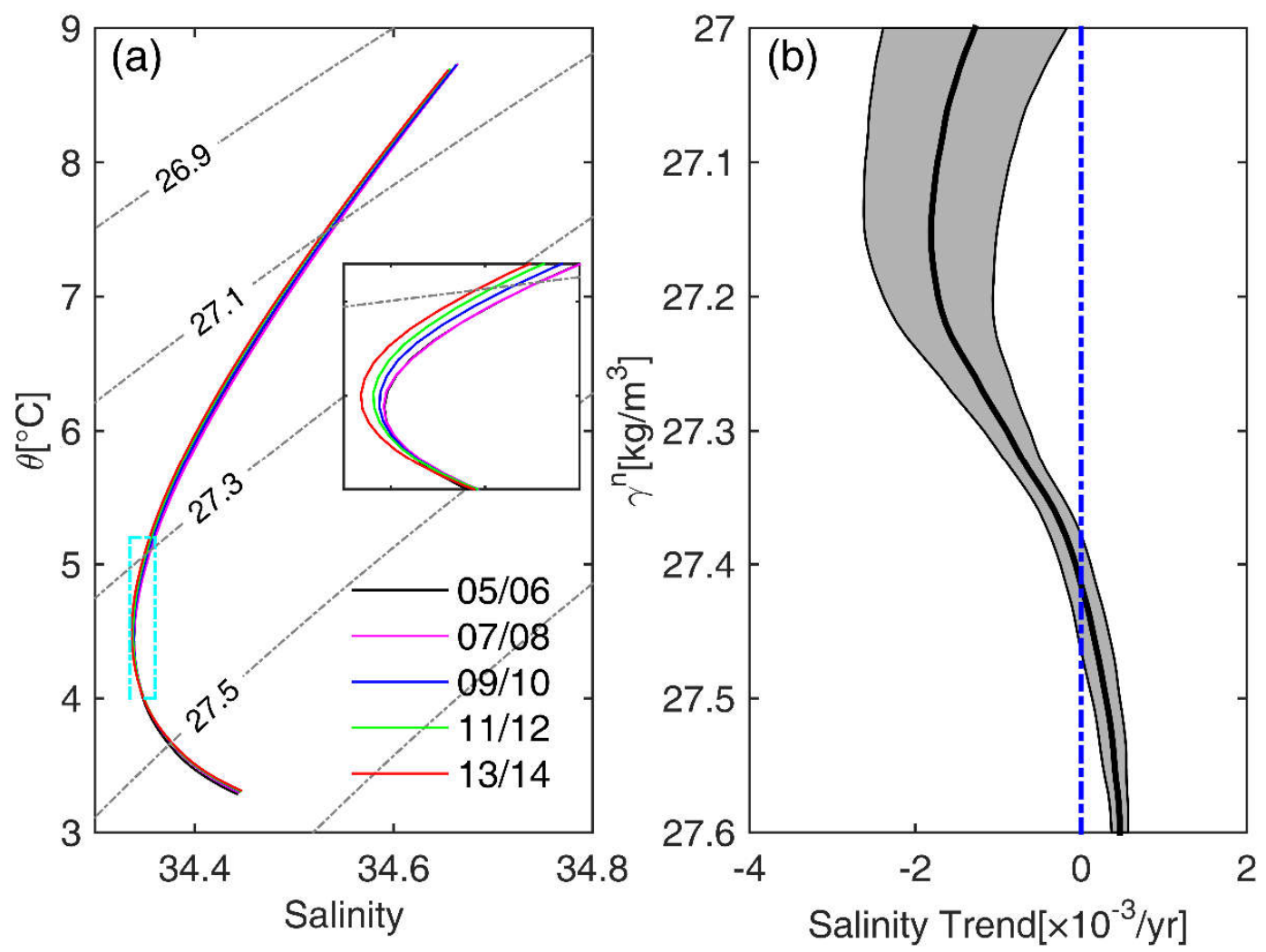

Supplementary 1 (a) Biennial mean $\theta-S$ diagram averaged over Region A for JAMSTEC data with $\gamma^{n}$ surfaces superimposed (grey solid-dotted lines). The inserted figure is the magnification of the area delineated by cyan solid-dotted box. The corresponding time for each $\theta-S$ curve is listed in the bottom-right corner (i.e. 05/06 for 2005-2006). (b) Salinity trend along $\gamma^{n}$ surfaces for period Jan 2005 - Dec 2014 is displayed by the thick black line, and the $95 \%$ confidence intervals ( $F$-test) are represented by the light grey shadings, calculated from the JAMSTEC data. 


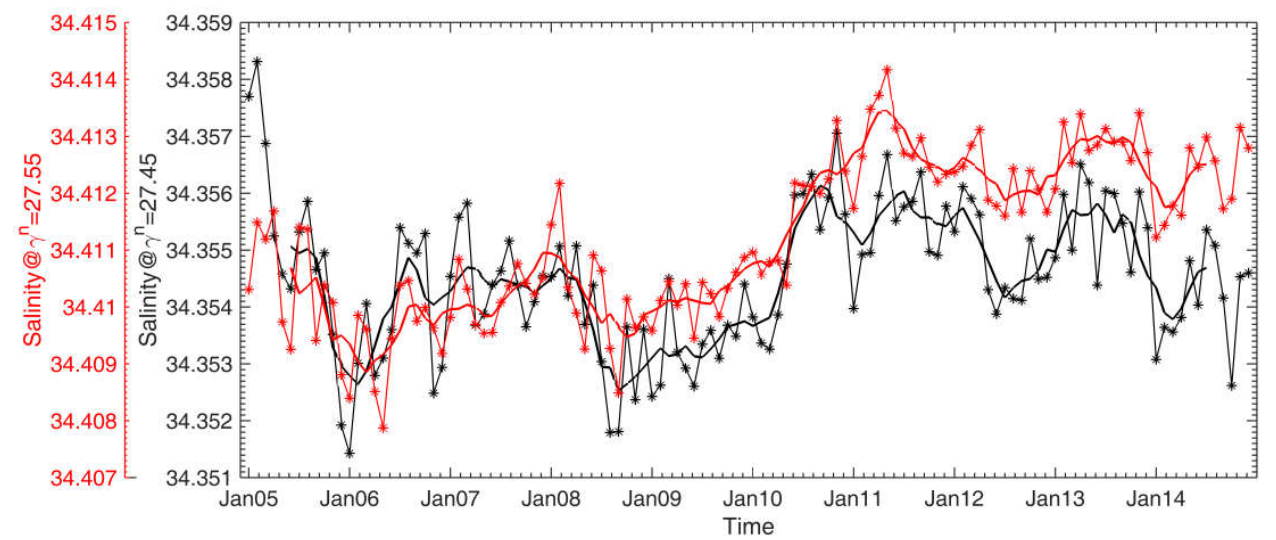

Supplementary 2 Time series of monthly salinity on the $27.45 \gamma^{n}$ (black) and $27.55 \gamma^{n}$ (red) surfaces, calculated from the IPRC data and averaged over the Region A shown in Fig. 2. Thin star lines and thick lines represent monthly and 13-month running mean values, respectively.

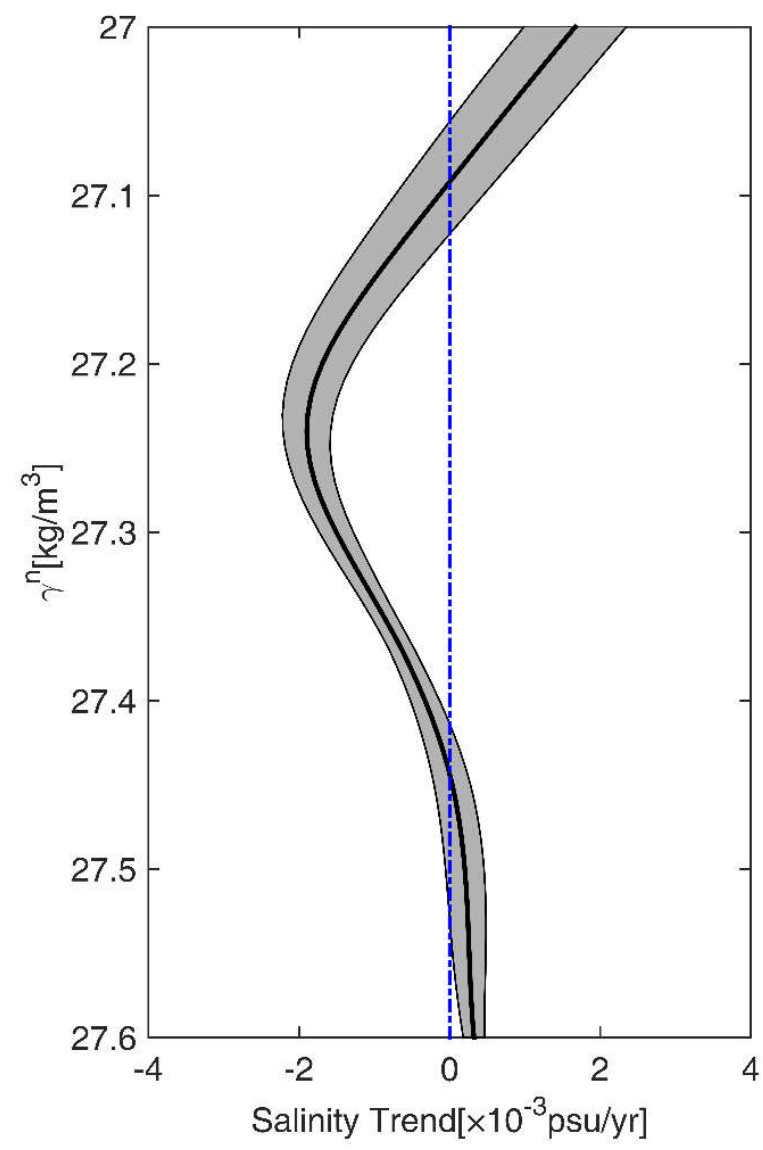


Supplementary 3 Salinity trend along $\gamma^{n}$ surfaces for period Jan 2005 - Dec 2014 is displayed by the thick black line, and the $95 \%$ confidence intervals ( $F$-test) are represented by the light grey shadings, calculated from the SODA data. 